\title{
Assessment of Knowledge and Attitudes of Expectant Mothers towards HIV Screening and Counselling at Jachie-Pramso in the Ashanti Region of Ghana
}

\author{
Christiana Asiedu1 ${ }^{*}$, Evans Opoku Agyemang2, Emmanuel Appiah Agyei² \\ ${ }^{1}$ Department of Adult Health, School of Nursing and Midwifery, College of Health and Allied Sciences, University of Cape Coast, \\ Cape Coast, Ghana, \\ ${ }^{2}$ Department of Science Education, Faculty of Science and Technology Education, College of Education Studies, University of \\ Cape Coast, Cape Coast, Ghana \\ Email: *casiedu@ucc.edu.gh
}

How to cite this paper: Asiedu, C., Agyemang, E.O. and Agyei, E.A. (2019) Assessment of Knowledge and Attitudes of Expectant Mothers towards HIV Screening and Counselling at Jachie-Pramso in the Ashanti Region of Ghana. World Journal of AIDS, 9, 183-194.

https://doi.org/10.4236/wja.2019.94014

Received: November 7, 2019

Accepted: December 28, 2019

Published: December 31, 2019

Copyright $\odot 2019$ by author(s) and Scientific Research Publishing Inc. This work is licensed under the Creative Commons Attribution International License (CC BY 4.0).

http://creativecommons.org/licenses/by/4.0/

c) $\underset{\mathrm{EY}}{\mathrm{B}}$ Open Access

\begin{abstract}
Background: The prevention of mother to child transmission (PMTCT) of human immunodeficiency virus (HIV) is paramount in safeguarding the lives of unborn children and young babies. The study sought to examine the knowledge and attitudes of expectant mothers towards HIV screening and testing in the Jachie-Pramso Community of the Ashanti Region. Methods: The study adopted a descriptive survey approach as its research design. The population of the study comprised 158 expectant mothers who were registered and attended regular antenatal care sessions at the community hospital. The census approach to sampling was adopted for the study. A structured questionnaire was used as the tool for data collection. Chi-square and descriptive statistics were used to analyse the data. Results: The findings from the study indicated that awareness level of HIV and its related issues were high among expectant mothers. It was also found that attitude of healthcare workers, community members and sexual partners are the main factors that prevent expectant mothers from patronising voluntary counselling and testing (VCT) services. It was generally, recommended that intensive educational programmes be instituted to sensitize both healthcare workers and the general public on discriminative behaviours. Conclusion: Most of the expectant mothers have knowledge of HIV and attitudes of the expectant mothers towards VCT of HIV were positive. The healthcare facility and its professionals may consider training the expectant mothers so they can act as snow-ballers in the dissemination of relevant health education and coerce other expectant mothers in the community to participate in the VCT and HIV programmes.
\end{abstract}




\section{Keywords}

Acquired Immune Deficiency Syndrome, Expectant Mothers, Human Immunodeficiency Virus, Voluntary Counselling and Test

\section{Introduction}

The Human Immunodeficiency Virus/Acquired Immune Deficiency Syndrome (HIV/AIDS) was first observed worldwide in the year 1981 and ever since, has proven to pose a great problem in most parts of the world today, especially in the way people relate with each other physically [1]. It is estimated that about $95.0 \%$ of the 36.1 million people living with HIV/AIDS can be found in the developing world; especially in the sub-Saharan Africa [2]. It is also being considered as one of the greatest challenges to the human race and modern medicine in the 21st Century [3], considering the fact that no medically approved cure has been found for the disease.

In Ghana, HIV was first reported in March 1986 and has since seen a steady rise in numbers [1]. Just like the rest of Africa, sexual (especially heterosexual) contact as well as mother-to-child transmission (MTCT) is the most common ways HIV/AIDS infections are spread [4]. As such, innocent children born to infected mothers acquire the infection and progress steadily to clinical disease. The 2014 Ghana Demographic and Health Survey (GDHS) report released indicates that the awareness level of HIV and AIDS is considered universal due to its high rates [5]. However, awareness of preventive measures, especially when it comes to pregnant women and lactating mothers' transmission to their children is on the low side. This is so when the 2013 National HIV/AIDS policy adopted strategies to eliminate MTCT completely after previous policies chalked little success [6].

The prevention of mother to child transmission (PMTCT) of HIV is achieved through its incorporation into antenatal education programmes for pregnant women. Thus, HIV tests are either routinely offered as part of antenatal care or are offered to pregnant women thought to be at high risk of exposure to HIV. This has helped to reduce rates of mother to child transmission dramatically [7]. According to the Ghana HIV/AIDS Strategy Framework, mother to child transmission (MTCT) is estimated to account for about $15.0 \%$ of all HIV transmissions in Ghana [8]. In addition, one of the key interventions of the strategy is to prevent MTCT through the use of Voluntary Counselling and Testing (VCT). A number of VCT programmes initiated between 2000 and 2010 in various parts of the country proved successful with recorded declines in prevalence [6].

Available statistics from the Ghana AIDS Commission indicate that MTCT contributes to about $15.0 \%$ of all HIV transmissions in Ghana and further concluded that one of the key interventions to implement in preventing MTCT is through Voluntary Counselling and Testing [6]. A total of 601,726 pregnant women 
were tested for HIV in Ghana in 2013 [9]. Of this number, 12,583 representing $2.1 \%$ were found to be positive; however, only $66 \%$ (8299) of the infected were given treatment to facilitate the PMTCT, representing a deficit of about 34\% [9]. The study therefore sought to assess the knowledge and attitudes of expectant mothers towards HIV screening and counselling at Jarchie-Pramso in the Ashanti Region of Ghana.

\section{Research Questions}

The following research question questions were formulated to guide the study to attain its set objectives:

1) What is the level of knowledge of expectant mothers on HIV counselling and testing?

2) What is the attitudes of expectant mothers towards the patronization of HIV counselling and testing?

3) What factors influence expectant mothers' patronisation of VCT of HIV?

\section{Methods}

\subsection{Research Design}

The descriptive survey approach was adopted as the research design for the study. This type of design is non-experimental in nature because it studies the relationship between variables in natural setting rather than artificial setting. With respect to the current study, an attempt was made to describe the current state of knowledge and attitudes of expectant mothers in the Jachie-Pramso Community. The method adopted allowed the study to assess the knowledge and attitudes and describe its current state as it pertains to the community without necessarily investigating why it is so.

\subsection{Study Area}

The Jachie-Pramso community is located in the Bosomtwe district in the Ashanti Region of the Republic of Ghana. The District is mainly famous for housing one of Ghana's famous natural sites; the Lake Bosomtwe, with an estimated population of about 93,910. Most of the inhabitants in the district are Ashantis. However, there are some Ewes, Fantes and members of other ethinic groups present. The main occupation of the inhabitants is farming and trading. Crops mainly produced include maize, cassava, yam, vegetables, plantain, etc. With respect to the communities under study, they share a community hospital (St. Michael's Catholic Hospital), which is located at Pramso. There are also a number of educational institutions in the community [5].

\subsection{Target Population}

The population of the study comprised all pregnant women in the Jachie-Pramso community. However, the accessible population was made up of all pregnant women who were registered with the community hospital for antenatal care be- 
tween January-June, 2017. The choice of this group stems from the fact that they have been educated on HIV related issues and other infections that could endanger the lives of their unborn children. In addition, a number of them have been tested. Thus, they have knowledge of their HIV status. According to the records obtained from the hospital, the registered pregnant women were 158.

\subsection{Sampling Procedure}

In all, 158 pregnant women made up the sample size for the study. The census approach was used to capture information from all the pregnant women that fell in that group.

\subsection{Data Collection Instruments}

The instrument used for the study was a structured questionnaire. The questions adopted were closed-ended questions to keep responses accurate and concise. The first section collected information on respondents' background characteristics. The second to fourth sections dealt with gathering information to answer each of the research questions formulated for the study so as to attain the objectives set for the study.

\subsection{Data Collection Procedure}

An introductory letter was sought from the department of Health Science Education and submitted to the hospital administrator to give clearance for the data collection process. The collection of data was done by the researchers themselves. Due to the anticipated language barrier, the researchers guided the expectant mothers to successfully complete the process of data collection. Respondents were assured of anonymity and confidentiality. The researchers used a week to complete the data collection process.

\subsection{Data Processing and Analysis}

In order to address the research questions formulated, the data were filtered to remove any irrelevant responses and coded. They were then analysed using Statistical Package for the Social Sciences (SPSS v.21). Descriptive and Chi-square statistics were used to analyse the data. The data were organised into tables for easy reading and interpretation of results. In order to examine the relationship between the age of expectant mothers and their perception of VCT services, a Chi-square analysis was computed and analysed to support the findings.

\section{Results}

Table 1 presents the results of respondents' background information. The results indicate that $48.1 \%$ (76) of the respondents were between the ages 30 and 39 years. With regards to respondent's marital statuses, a slight majority, 50.6\% (80), of the respondents revealed that they were married. Basic education recorded the highest level of education for majority, $60 \%$ (94), of the respondents. In a community where most of the residents engage in subsistence farming coupled 
Table 1. Background information of respondents.

\begin{tabular}{|c|c|c|}
\hline Background information & Frequency (N) & Percentage (\%) \\
\hline \multicolumn{3}{|l|}{ Age } \\
\hline $15-19$ yrs & 14 & 8.9 \\
\hline $20-29$ & 56 & 35.4 \\
\hline $30-39$ & 76 & 48.1 \\
\hline Above 40 & 12 & 7.6 \\
\hline \multicolumn{3}{|l|}{ Marital status } \\
\hline Married & 80 & 50.6 \\
\hline Single & 68 & 43.0 \\
\hline Divorce & 10 & 6.3 \\
\hline \multicolumn{3}{|l|}{ Religion } \\
\hline Christian & 128 & 81.0 \\
\hline Muslim & 26 & 16.5 \\
\hline Traditional & 4 & 2.5 \\
\hline \multicolumn{3}{|l|}{ Highest level of education } \\
\hline Basic Education & 94 & 59.8 \\
\hline Secondary & 38 & 24 \\
\hline Tertiary & 14 & 8.7 \\
\hline No formal education & 12 & 7.5 \\
\hline \multicolumn{3}{|l|}{ Employment status } \\
\hline Employed & 110 & 69.6 \\
\hline Unemployed & 48 & 30.4 \\
\hline
\end{tabular}

Source: Field Work, 2017.

with a quite high prevalence of teenage pregnancy, it is not surprising that most of the expectant mothers do not make it to the tertiary level of education. In a related development, $69.6 \%$ (110) said they were employed in various forms of occupational activities.

Table 2 presents the results of responses regarding respondents' awareness of HIV. The figures indicate that $93.7 \%$ (148) of the respondents have heard of HIV/AIDS. Regarding testing, 83.5\% (132) of the expectant mothers indicated that they have been tested. Thus, about 16 women, despite knowing of the virus, are yet to be tested. Table 2 presents responses of respondents regarding their VCT services. The figures indicate that a majority of $72.2 \%$ (114) of the respondents have heard of VCT services. Consequently, 70.9\% (112) of the expectant mothers believe VCT services is good. Thus, out of the 114 expectant mothers who have heard of VCT, two do not agree that the service is a good thing. Upon eliciting responses to whether an expectant mother with HIV can prevent transmission to her child, majority of the respondents $89.9 \%$ (142) agreed that the transmission from mother to child can be prevented. On specific means of MTCT of HIV, Table 2 presents the responses of the expectant mothers. 
Table 2. Awareness and self-testing of HIV.

\begin{tabular}{lcc}
\hline \multirow{2}{*}{ Item } & \multicolumn{2}{c}{ Response } \\
\cline { 2 - 3 } & Yes & No \\
\hline Have you ever heard of HIV? & $148(93.7)$ & $10(6.3)$ \\
$\begin{array}{l}\text { Have you been tested to HIV? } \\
\text { Knowledge on Voluntary Counselling and Testing (VCT) }\end{array}$ & $132(83.5)$ & $26(16.5)$ \\
Have you ever had counselling on HIV testing? & $114(72.2)$ & $44(27.8)$ \\
In your own experience, is HIV counselling and testing is a good thing? & $112(70.9)$ & $46(29.1)$ \\
Can an expectant mother with HIV infect her child too? & $142(89.9)$ & $16(10.1)$ \\
\hline
\end{tabular}

Source: Field Work, 2017.

A look at Table 3 shows the results of respondents on the means by which HIV infected expectant mothers can transmit the virus to their unborn or newly born babies. The figures indicate that most of the pregnant women 57\% (90) believe that transmission of the virus can occur through the delivery process. With regards to transmission through breastfeeding, 29.1\% (46) believe it is possible for the virus to be passed whiles breastfeeding.

A look at Table 4 reveals that on a whole, most of the expectant mothers do have a positive attitude towards the VCT of HIV. For instance, 62\% (98) of the respondents indicated their willingness to get tested for HIV without any advice from another person. This finding is very relevant as it forms the core of the "voluntary" in the VCT programme. They indicated that they would recommend the test to others $(138 ; 87 \%)$, relate closely with those who test positive (120; $76 \%$ ), and testing for HIV for expectant mothers is important (150; 95\%).

Table 5 presents the results of responses on the factors perceived to influence expectant mothers' patronisation of VCT services. The figures revealed that 136 $(86.1 \%)$ of the respondents have heard of VCT. The figure indicates a high level of awareness among the expectant mothers, which is very relevant in determining whether they would patronise the service. In assessing the factors, the figures form Table 6 revealed that a majority of $83.5 \%$ (132) of the respondents feel that age is not a barrier to VCT, thus, they indicated they do not feel too young to attend VCT. With regards to the impact that work schedules (time) have on the patronisation of VCT services, 68.4\% (108) of the respondents disagreed that their work schedules prevented them from seeking VCT of HIV. Similarly, most, $87.3 \%$ (138), of the expectant mothers specified that their personal and traditional beliefs do not prevent them from partaking in VCT services. The trend of responses was no different for the impact of religion as $88.6 \%$ (140) also specified that their religious beliefs do not prevent them from getting tested.

An assessment of the impact of cost revealed that $67.1 \%$ (106) of the respondents indicated that the cost of hospital services does not scare them form patronising VCT services. In all, a majority of $70.9 \%$ (112) of the respondents agreed that the attitude of some health care professionals prevented them from patronising VCT services. The figures revealed that $75.9 \%$ (120) of expectant 
Table 3. Mother to child transmission (MTCT) of HIV.

\begin{tabular}{ccc}
\hline Preventive Measures & Frequency & Percent \\
\hline Delivery & 90 & 57.0 \\
Breastfeeding & 46 & 29.1 \\
During pregnancy & 22 & 13.9 \\
Total & 158 & 100.0 \\
\hline
\end{tabular}

Source: Field Work, 2017.

Table 4. Attitudes of expectant mothers towards VCT of HIV.

\begin{tabular}{lcc}
\hline \multicolumn{1}{c}{ Items } & \multicolumn{2}{c}{ Responses } \\
\cline { 2 - 3 } & $\begin{array}{c}\text { Yes } \\
\text { n (\%) }\end{array}$ & n (\%) \\
\hline Would you willingly go for an HIV test without anyone's advice? & $98(62)$ & $60(38)$ \\
$\begin{array}{l}\text { Would you recommend a fellow expectant mother for HIV } \\
\text { counselling and testing? }\end{array}$ & $138(87.3)$ & $20(12.7)$ \\
$\begin{array}{l}\text { Can you relate closely with a friend who after testing is confirmed } \\
\text { HIV positive? }\end{array}$ & $120(75.9)$ & $38(24.1)$ \\
$\begin{array}{l}\text { On a whole, do you consider the counselling and testing of } \\
\text { expectant mothers on HIV important? }\end{array}$ & $150(94.9)$ & $8(5.1)$ \\
\hline
\end{tabular}

Source: Field Work, 2017.

Table 5. Factors influencing pregnant mothers' decision in patronising VCT.

\begin{tabular}{lcc}
\hline \multicolumn{1}{c}{ Items } & \multicolumn{1}{c}{ Responses } \\
\cline { 2 - 3 } & Yes N (\%) No N (\%) \\
\hline Have you ever heard of VCT? & $136(86.1)$ & $22(13.9)$ \\
Age (do you feel you are too young to attend VCT)? & $26(16.5)$ & $132(83.5)$ \\
Time (does your work schedule prevent you from going for VCT)? & $50(31.5)$ & $108(68.4)$ \\
Beliefs (does your traditional/personal beliefs prevent you from VCT)? & $20(12.7)$ & $138(87.3)$ \\
Religion (does your religious believes prevent you from going for VCT)? & $18(11.4)$ & $140(88.6)$ \\
Does your community hospital offer VCT services? & $132(83.5)$ & $26(16.5)$ \\
Does the cost of hospital services scare you from seeking VCT? & $52(32.9)$ & $106(67.1)$ \\
Does the attitude of healthcare professional deter you from seeking VCT? & $112(70.9)$ & $46(29.1)$ \\
Does the attitude of community members deter you from patronising VCT? & $120(75.9)$ & $38(24.1)$ \\
\hline
\end{tabular}

Source: Field Work, 2017.

mothers indicated that the attitude of community members deter them from patronising VCT. However, with regards to the attitude of their partners (sexual), only a slight majority, $54.4 \%$ (86), specified that their partners did not prevent them from seeking VCT services.

Table 6 presents a cross tabulation of expectant mothers' age against their perception of the VCT services rendered by the community hospital. According 
Table 6. Chi-Square square test and cross tabulation of age and expectant mothers' Perception about the importance of VCT testing.

\begin{tabular}{cccccc}
\hline & Yes n (\%) & No n (\%) & Total & X2 & p-value \\
\hline Age & & & & $\mathbf{2 3 . 3 8}$ & $\mathbf{0 . 0 0 0}$ \\
\hline $15-19$ yrs & $10(71.4)$ & $4(28.6)$ & 14 & & \\
$20-29$ & $56(100)$ & $0(0.0)$ & 56 & & \\
$30-39$ & $74(97.4)$ & $2(2.6)$ & 76 & & \\
Above 40 & $10(83.3)$ & $2(16.7)$ & 12 & & \\
Total & $150(94.9)$ & $8(5.1)$ & 158 & & \\
\hline
\end{tabular}

Source: Field Work, 2017.

to UNICEF (2002), there is a general low acceptance of Voluntary Counselling and Testing (VCT) services by young pregnant women according to research findings. This empirical finding is supported by the results from Table 5. The figures indicate that among the total of 8 expectant mothers who specified that the VCT service is not important, majority (4) were between the ages 15 and 19 years.

A Chi-Square Square test for independence computed indicates there was a significant relationship between age and perception of VCT service. The ages relation to perception of VCT service was significantly related on $\chi^{2}(3, \mathrm{~N}=158)=$ 23.38, $p<0.00$.

\section{Discussion}

The results of the study indicated that the respondents have heard of HIV/AIDS, and most of them have been tested. Most of those who have not been tested do not see the need due to fear of stigmatisation. Awareness of HIV has a significant bearing on voluntarily opting for testing, instituting preventive measures and ultimately, preventing mother to child transmission of the virus [10]. With respect to the few who do not know about HIV, they need more education on the issue, since education plays a pivotal role in the acceptance of VCT [11] [12] [13]. However, for expectant mothers who attend antenatal care but do not know about HIV, there is the assumption that such group may not be attending classes regularly.

At least each expectant mother had an idea about the possible means that an infected mother can transmit the virus to her child. The consequence of knowing about MTCT of HIV leads to ensuring preventive measures and is key to saving the lives of millions of young children as well as guaranteeing a better future for them [12] [13] [14]. The results suggest that most of the expectant mothers showed awareness of HIV and preventive measures for controlling its spread. Also, awareness of possible mother to child HIV transmission exists among the pregnant women as well as modes of transmission. The awareness level appears to be high among the pregnant women, mainly because all of them were sampled for the group that attends antenatal care at the community hospital. Thus, it is 
expected that they may have had some tutoring about Pregnancy related HIV issues.

Majority of the expectant mothers opted to get tested on their own accord. They might influence others to get tested as well. Consequently, the expected mothers revealed they would recommend other expectant mothers for HIV counselling and testing. In related development, the expectant mothers were asked if they could relate closely with friends who upon being tested, were found to be positive. The responses revealed that they could relate with friends tested positive for HIV. In the wake of a number of stigmatisation cases against persons living with HIV, having a group of people who have been tested negative ready to compromise with, living and relating with other persons tested positive is a step in the right direction. The expectant mothers agreed that they considered the counselling and testing of expectant mother on HIV important. The importance of VCT cannot to be underestimated. Voluntary Counselling and Testing plays a pivotal role in PMTCT of HIV and safeguarding lives, especially among pregnant women who patronise antenatal care services [1] [10] [15]. In assessing the factors, the respondents feel that age is not a barrier to VCT, thus, they indicated they do not feel too young to attend VCT. This finding does not come as a surprise, considering earlier observations revealed only few of the respondents were below the age of 18 . Consequently, majority of the expectant mothers are adults and are expected to decide for themselves. Nonetheless, research findings have revealed that there is general dislike for VCT among young (teenage) pregnant women [10] [15]. The respondents disagreed that their work schedules prevented them from seeking VCT of HIV. It is expected that the minority of expectant mothers who work in public or private institutions where there is a busy schedule might have some challenges attending antenatal care as a result of time and fatigue. Similarly, the expectant mothers specified that their personal and traditional beliefs do not prevent them from partaking in VCT services. The trend of responses was no different for the impact of religion as most of them specified that their religious beliefs do not prevent them from getting tested. In all, factors such as work schedule (time), personal/traditional beliefs and religious beliefs appear not to have any impact on majority of the expectant mothers' patronisation of VCT.

Further observation revealed that the community hospital offers VCT services for expectant mothers. Also, an assessment of the impact of cost revealed that majority of the respondents indicated that the cost of hospital services does not scare them form patronising VCT services. Considering that majority of the general healthcare services rendered to expectant mothers are free under the $\mathrm{Na}$ tional Health Insurance Scheme, except for some specialized services, their responses do not come as a surprise. Despite the cost of hospital services not being a hindrance to most of the expectant mothers, the attitude of the healthcare workers was. In all, a majority of the respondents agreed that the attitude of some health care professionals prevented them from patronising VCT services. This finding is in agreement with the findings of a study conducted in Uganda 
where most healthcare professionals demonstrate negative attitudes towards expectant mothers, especially younger pregnant women and teenagers [10].

In addition to the attitude of healthcare professionals, the attitudes of some community members also appear to contribute to expectant mothers' decision to seek VCT. The study revealed that majority of expectant mothers indicated that the attitude of community members deter them from patronising VCT. However, with regards to the attitude of their partners (sexual), only a slight majority specified that their partners did not prevent them from seeking VCT services. Still, quite a significant number had their partners preventing them. In African societies, most women cannot take decisions on their own; thus, a lot of married women refrain from VCT counselling services that promote PMTCT due to fear of being rejected by their spouses, stigmatisation and discrimination, fear of not breast feeding, fear of congenital anomalies, interruption of check-ups, home and premature delivery [10] [12] [15].

Expected mothers' age has an influence on their perception of the VCT service provided by the community hospital. In conjunction with previous findings, pregnant teenagers may have a negative perception of the VCT service as a result of the treatment they receive from the healthcare providers. Empirical findings observed form a number of developing countries show that teenage or younger pregnant women fear stigmatisation and being treated harshly by health workers [10] [16]. With a high level of awareness among expectant mothers, it is expected that most of them will be able to cite some preventive measures with regards to HIV. Therefore, in accessing expectant mothers' knowledge on preventing HIV infection, they were asked to identify some preventive measures they would put in place to ensure they stay protected from an infection. The results indicate that generally, the expectant mothers have some ideas on preventive measures. Key measures identified include, abstinence, being faithful to their sexual partners, the use of condoms, avoiding unprotected sex and the sharing of sharp instruments with others. Among the listed preventive measures, the most notable measure recorded by the pregnant women was the use of a condom for protection. These preventive measures are among the most common measures that can be adopted for the prevention of HIV infection [17] [18].

\section{Conclusion}

Most of the expectant mothers appear to have knowledge of HIV and ways by which they can prevent it. Precisely, most of the expectant mothers know about HIV and AIDS, they also know about their current HIV statuses, which is very relevant in the determination of physical relationships with their partners as well as the PMTCT of the virus. Attitudes of the expectant mothers towards VCT of HIV appear to be positive as most of the women cited the willingness to get tested voluntarily as well as recommending the service to other expectant mothers. With regards to the factors influencing the patronisation of VCT services, factors such as age, time (work schedule), personal beliefs and religious beliefs 
did not prevent expectant mothers from seeking counselling and testing services voluntarily. However, other factors such as attitudes of healthcare professionals, community members as well as sexual partners were identified to prevent expectant mothers from patronising VCT services. In conclusion, personal factors do not impede the patronisation of VCT as compared to social factors.

\section{Ethics Approval and Consent to Participate}

Approval of the study was sought from the Department of Science Education of University of Cape Coast. The study was approved by the leaders of the JachiePramso Community. Verbal informed consent was sought form the study participants.

\section{Availability of Data and Materials}

The dataset will be available on request due to ethical reasons.

\section{Acknowledgements}

We acknowledge all my mentors and various writers from whom references were made. We would like to thank all other individuals who provided the needed support for the completion of this study.

\section{Conflicts of Interest}

The authors declare that we have no competing interest.

\section{References}

[1] Kwofie, G.S. (2008) Acceptance of HIV Counselling and Testing Among Pregnant Women in the Kumasi Metropolis. MPH Thesis, KNUST, Kumasi.

[2] UNAIDS (2000) Joint Country Mission Report. International Partnership against AIDS in Africa, Ghana, 12-16 October 1999.

[3] Mujumali, N. (2011) Knowledge and Attitude on Prevention of Mother to Child transmission of HIV among Pregnant Women Attending Reproductive and Child Health Clinic at Temeke District Hospital in Dar Es Salaam. Master's Thesis, Muhimbili University of Health and Allied Sciences, Dar es Salaam, Tanzania.

[4] Ghana Statistical Service (GSS) (2016) Ghana Health Service: Family Health Division 2015 Annual Report. Ministry of Health, Accra.

[5] Ghana Statistical Service (GSS), Ghana Health Service (GHS), ICF International (2015) Ghana Demographic and Health Survey 2014: Key Indicators Report. GSS, Baltimore, MD.

[6] National AIDS Control Programme/Ghana AIDS Commission (2014) Status Report.

[7] Maheswaran, H. and Bland, R.M. (2009) Preventing Mother-to-Child Transmission of HIV in Resource-Limited Settings. Future Virology, 4, 165-175. https://doi.org/10.2217/17460794.4.2.165

[8] Ghana AIDS Commission (2013) National HIV and AIDS, STI Policy Revised Report.

[9] Ghana AIDS Commission (2013) Country AIDS Progress Report. 
[10] Meeme, M. (2013) Factors Influencing Utilization of Prevention of Mother to Child Transmission (PMTCT) of HIV/AIDS in Uganda. Master's Thesis, the University of Makere, Uganda.

[11] World Health Organization (2013) Page 1 of 9 Operational Considerations for Preventing the Mother-to-Child Transmission (PMTCT) of HIV in the 2013 WHO Consolidated Guidelines on the Use of Antiretroviral Drugs for Treating and Preventing HIV Infection.

[12] Abraham, S.C.S., Sheeran, P., Spears, R. and Abrams, D. (2003) Healthbeliefs and the Promotion of HTV-Preventive Intentions amongst Teenagers: A Scottish Perspective. Health Psychology, 11, 363-370.

https://doi.org/10.1037//0278-6133.11.6.363

[13] Armstrong-Bassett, M.T. (2002) Ensuring a Public Health Impact of Programs to Reduce HIV Transmission from Mother to Infant: The Place of Voluntary Counselling and Testing. American Journal of Public Health, 92, 347-351. https://doi.org/10.2105/AJPH.92.3.347

[14] WHO (2010) Prevention of Mother to Child Transmission of HIV/AIDS in Africa. AIDS Journal, 65.

[15] Martin-Herz, S.P. (2006) Perceived Risks and Benefits of HIV Testing and Predictors of Acceptance of HIV Counselling and Testing among Pregnant Women in Zimbabwe. International Journal of STD \& AIDS, 17, 835-841. https://doi.org/10.1258/095646206779307630

[16] UNICEF (2009) Mother to Child Transmission of HIV/AIDS. Fact Sheet 112/2002, New York.

[17] Curran, J.W., Lawrence, D.N., Jaffe, H., Kaplan, J.E., Zyla, L.D., Chamberland, M., Weinstein, R., Lui, K.-J., Schonberger, L.B., Spira, T.J., Alexander, W.J., Swinger, G., Ammann, A., Solomon, S., Auerbach, D., Mildvan, D., Stonebumer, R., Jason, J.M., Haveikos, H.W. and Evatt, B.L. (1984) Acquired Immunodeficiency Syndrome (AIDS) Associated with Transfusions. The New England Journal of Medicine, 310, 69-75. https://doi.org/10.1056/NEJM198401123100201

[18] Gottlieb, D., Shetty, A.K., Bassett, M.T., Mapfungautsi, R.M. and Katzenstein, D. (2000) Infant Feeding: Knowledge, Attitudes, and Practices among Women in Zimbabwe. International AIDS Conference. 